\title{
Investigating e-mail overload in the South African banking industry
}

\section{E. Burger}

Centre for Information and Knowledge Management

University of Johannesburg

Johannesburg, South Africa

elsaburger@hotmail.com

\section{Rensleigh}

Centre for Information and Knowledge Management

University of Johannesburg

Johannesburg, South Africa

crensleigh@uj.ac.za

The information workers of today have a wide range of information sources available to make valuable decisions, so much so that it can lead to information overload. The purpose of this research was to investigate the extent of information overload in the South African banking industry. The empirical part of this study was done at the Standard Bank of South Africa, where 115 questionnaires were distributed to three categories of employees. It was found that e-mail is one of the most used computer-mediated applications and is used more than the World-Wide Web, instant messaging or peer-to-peer file sharing. Of the respondents, $65 \%$ felt overwhelmed by the amount of e-mails they received as $25 \%$ received more than 60 e-mails per day. A third of the respondents dedicated three hours or more to emails per day. Respondents agreed that the implementation of policies is important to ensure compliance with legislation, protection of privacy rights and copyright, and the filtering of spam. In conclusion, the respondents indicated that formal training in e-mail management should make a significant difference in the usage of e-mail within the organization and reduce e-mail overload.

Key words: Information overload, e-mail overload, South Africa, banking industry

Received 8 May 2007; accepted 13 August 2007

\section{Contents}


1. Introduction

1.1 Research problem

1.2 Rationale of the study

1.3 Research methodology

2. Information overload

3. Electronic communications

3.1 E-mail

3.2 Writing styles of e-mail users

3.3 Spam

4. E-mail overload

5. Effective management of e-mail within the organization

5.1 Policies

5.2 Monitoring and surveillance

5.3 Archiving

6. Conclusion and future areas of research

7. References

\section{Introduction}

The average employee is bombarded with increasing volumes of information. This causes a state where an individual's efficiency in using information in his or her work is hampered by a surplus amount of relevant and potentially useful information available to him of her, in other words, information overload (Bawden, Holtman and Courtney 1999).

Electronic-messaging systems, such as e-mail, have become the communication medium of choice in many organizations, and hold significant and valuable business data, information and knowledge. These systems have had a profound impact on the way in which personal and business communications are effected in the office. With e-mail having acquired mission-critical status in many organizations, a number of concomitant circumstances and consequences have arisen that present organizations, such as financial institutions (banks), with a variety of challenges that include the following:

- The impact on employees' productivity, owing to the time spent on e-mailing activities

- Employees' attitudes towards e-mail

- Compliance with corporate policies (e.g. policies governing electronic communication and computer use)

- Surveillance and monitoring of e-mail

- The quest for finding formal archiving solutions.

This survey intended to investigate the extent and impact of e-mail overload on the productivity of the information workers of the Standard Bank of South Africa.

\subsection{Research problem}

The following central research question was formulated for this study:

To what extent does the information overload phenomenon in the South African banking industry influence the productivity of the information workers, with special reference to e-mail overload?

\subsection{Rationale of the study}


One of the four major banks in South Africa was chosen for the empirical study mainly because banks manage and distribute information securely on a wide basis to customers and employees. This capability is a critical core competence and success factor of a bank, and most banks are very mature in their capability of managing information, including e-mail.

Banks are large investors in Information and Communication Technology (ICT) in commerce and usually have state-of-the-art investment, facilities and capabilities in this field. Banks have deep penetration of e-mail use by employees and executives. For the purpose of this study, the Standard Bank of South Africa was chosen.

\subsection{Research methodology}

A quantitative research approach was adopted and the population was selected from the Standard Bank of South Africa, Head Office, in Johannesburg. Du Plooy (2002) states that the objectives of a quantitative design are to predict, describe and explain quantities, degrees and relationships by collecting numerical data. Numerical data can be collected though a variety of methods and techniques, such as surveys, self-administrated questionnaires and experimental design.

For this study a questionnaire was compiled to investigate the extent, if any, to which information workers/employees are experiencing information overload and specifically email overload within the Standard Bank of South Africa. The questionnaire was done within the theoretical context of the research. Closed- and open-ended questions were included in the survey. Questionnaires were distributed by hand, and responses to each question had to be made in writing. The questionnaires were circulated to the following employee categories:

- Executives - 40 questionnaires were given out and 32 responses were received

- Operational managers - 50 questionnaires were given out and 50 responses were received

- Customer-interfacing managers - 25 questionnaires were given out and 24 responses were received.

After having gathered the empirical data, the completed questionnaires were given to Statcon (Statistical Consultation Service) at the University of Johannesburg for statistical processing and analysis.

\section{Information overload}

Information is very important and essential to every information worker in today's Information Age, whether it is collected or disseminated for personal or business use. Information generates from various resources and has different levels of quality and reliability.

Research done by Lyman and Varian (2003) has shown the incredible amounts of information resources that are produced and consumed every year. Information resources can either be recorded or stored on, for example, paper, film, magnetic or optical sources. It can further be distributed through electronic channels such as broadcasting, telephone or via the Internet.

The Information Age has replaced the Industrial Age and therefore people's knowledge is used rather than their physical skills. ICT has enabled information workers to create and disseminate this knowledge. Knowledge workers are hence an extension of the information 
worker, who can be anyone who has to make an informed decision using more than just the information supplied.

The Information Society does not just include technologies and communication mediums, but also the culture and economies this society or organization has to function in. This extended version is the network society. Networks are a wide variety of systems of interconnected components. Computer networks transfer information between computers and wireless applications, but most information workers are exposed to networks such as the Internet, the World-Wide Web (WWW), intranets in organizations and information portals.

Bawden, Holtman and Courtney (1999) indicate that there are no generally accepted definitions of information overload. The term 'information overload' is usually taken to present a state of affairs where an individual's efficiency in using information in his or her work is hampered by the amount of relevant, and potentially useful, information that is available to him or her. It is usually associated with a loss of control over the situation, and sometimes with feelings of being overwhelmed. They conclude that information overload occurs when the information received becomes a hindrance rather than a help.

The results of the questionnaire showed that respondents felt moderately overloaded by the amount of information they received every day. They were mostly overwhelmed by information received at work, and this influenced their physical well-being, relationships with colleagues, friends and family.

A summary of the results for the question on the impact of the volume of information is indicated in Table 1 and graphically depicted in Figure 1. From Figure 1, indicating the five different levels of well-being, it is evident that work performance was mostly influenced to a large and very large extent (70\%). Respondents indicated that they were physically influenced to a small to moderate extent $(60 \%+)$, while relationships with colleagues were influenced to a moderate to very large extent (77\%) by the amount of information received. Lastly, relationships with friends and family were influenced from a large to very large extend (63\%).

Respondents felt overloaded at work mostly and this could be because of the access to many ICT applications such as the WWW, e-mail, the intranet, faxes, cell phones, PDAs and smart phones. In addition, it could be because of the amount of information that had to be comprehended and processed to make business decisions in a short period of time. All of these elements inevitably influenced relationships with colleagues and with friends and family.

Table 1 Impact of the volume of information received on the well-being of employees

\begin{tabular}{|l|c|c|c|c|c|c|c|c|c|c|}
\hline & \multicolumn{2}{|c|}{$\begin{array}{c}\text { No } \\
\text { effect }\end{array}$} & \multicolumn{2}{c|}{$\begin{array}{c}\text { Small } \\
\text { extent }\end{array}$} & \multicolumn{2}{c|}{$\begin{array}{c}\text { Moderate } \\
\text { extent }\end{array}$} & \multicolumn{2}{c|}{$\begin{array}{c}\text { Large } \\
\text { extent }\end{array}$} & \multicolumn{2}{c|}{$\begin{array}{c}\text { Very large } \\
\text { extent }\end{array}$} \\
\cline { 2 - 11 } & Count & $\mathbf{\%}$ & Count & $\mathbf{\%}$ & Count & $\mathbf{\%}$ & Count & $\mathbf{\%}$ & Count & $\mathbf{\%}$ \\
\hline $\begin{array}{l}\text { Work } \\
\text { performance }\end{array}$ & $\mathbf{2}$ & $01,9 \%$ & $\mathbf{9}$ & $08,7 \%$ & $\mathbf{2 0}$ & $19,2 \%$ & $\mathbf{4 4}$ & $42,3 \%$ & $\mathbf{2 9}$ & $27,9 \%$ \\
\hline $\begin{array}{l}\text { Physical } \\
\text { well-being }\end{array}$ & $\mathbf{1 4}$ & $13,6 \%$ & $\mathbf{3 0}$ & $29,1 \%$ & $\mathbf{3 2}$ & $31,1 \%$ & $\mathbf{2 3}$ & $22,3 \%$ & $\mathbf{4}$ & $03,9 \%$ \\
\hline $\begin{array}{l}\text { Relationship } \\
\text { with } \\
\text { colleagues }\end{array}$ & $\mathbf{6}$ & $05,8 \%$ & $\mathbf{1 8}$ & $17,5 \%$ & $\mathbf{3 2}$ & $31,1 \%$ & $\mathbf{3 4}$ & $33,0 \%$ & $\mathbf{1 3}$ & $12,6 \%$ \\
\hline Relationship & & & & & & & & & &
\end{tabular}




\begin{tabular}{|l|l|l|l|l|l|l|l|l|l|l|}
$\begin{array}{l}\text { with } \\
\text { friends/family }\end{array}$ & $\mathbf{2 0}$ & $\mathbf{1 9 , 6 \%}$ & $\mathbf{3 6}$ & $35,3 \%$ & $\mathbf{2 3}$ & $22,5 \%$ & $\mathbf{1 8}$ & $\mathbf{1 7 , 6 \%}$ & $\mathbf{5}$ & $04,9 \%$ \\
\hline
\end{tabular}

Figure 1 Impact of the volume of information received on the well-being of employees

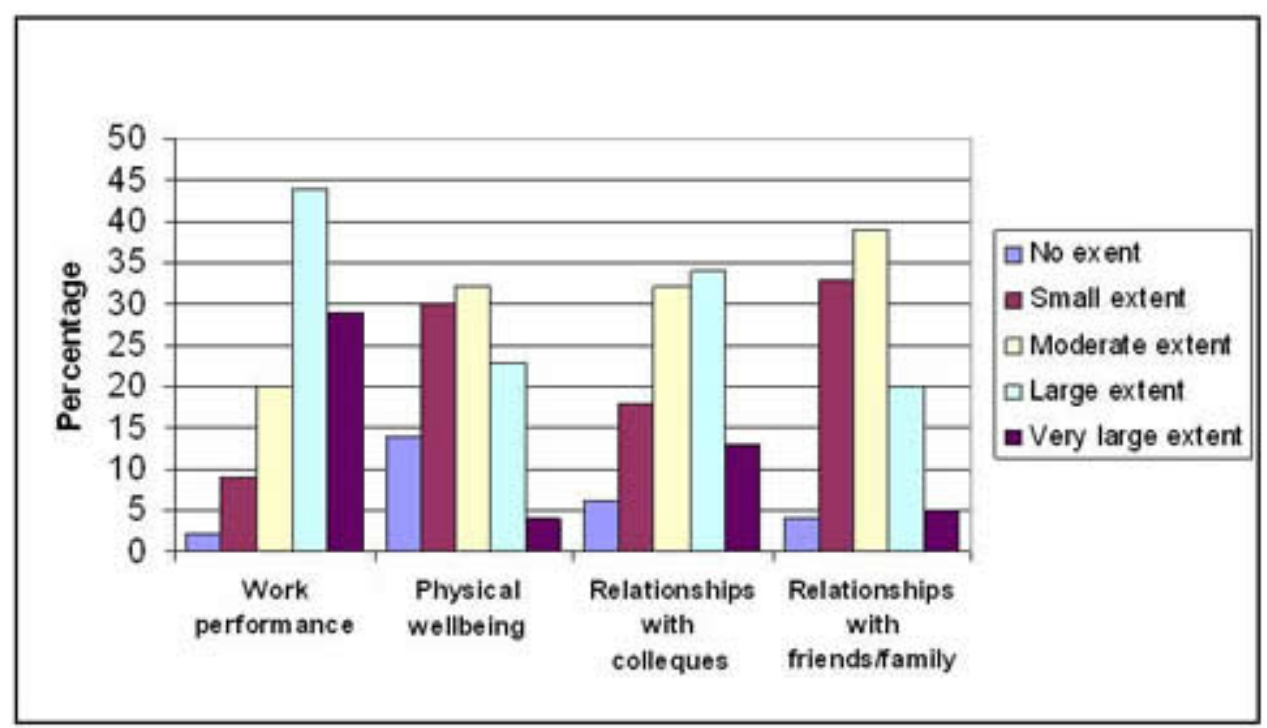

The questions relating to well-being were factor analysed using the Crombach Alpha measure of internal consistency that was calculated at 0,79 . An analysis of variances (ANOVA) test was done on the well-being scale of the three managerial groupings, namely executive, operational and customer interfacing managers. This was done to test the equality, that is, if there was a significant difference between the three categories of managerial groups. The outcome of the statistical analysis was that there was no significant difference between the mean wellness levels of the three managerial categories as indicated in Table 2 and Figure 2.

Table 2 Analysis of variance of the well-being for the three managerial categories

\begin{tabular}{|l|c|c|c|}
\hline Position/Job level & Mean & Std deviation & N \\
\hline Customer interfacing managers (CIM) & 3,3068 & 0,81989 & 22 \\
\hline Operational managers (OP) & 2,9635 & 0,88575 & 48 \\
\hline Executives (E) & 3,1641 & 0,76625 & 32 \\
\hline Average/Total & $\mathbf{3 , 1 0 0 5}$ & $\mathbf{0 , 8 3 9 3 6}$ & $\mathbf{1 0 2}$ \\
\hline
\end{tabular}

Figure 2 Variance of the well-being for the three managerial categories 


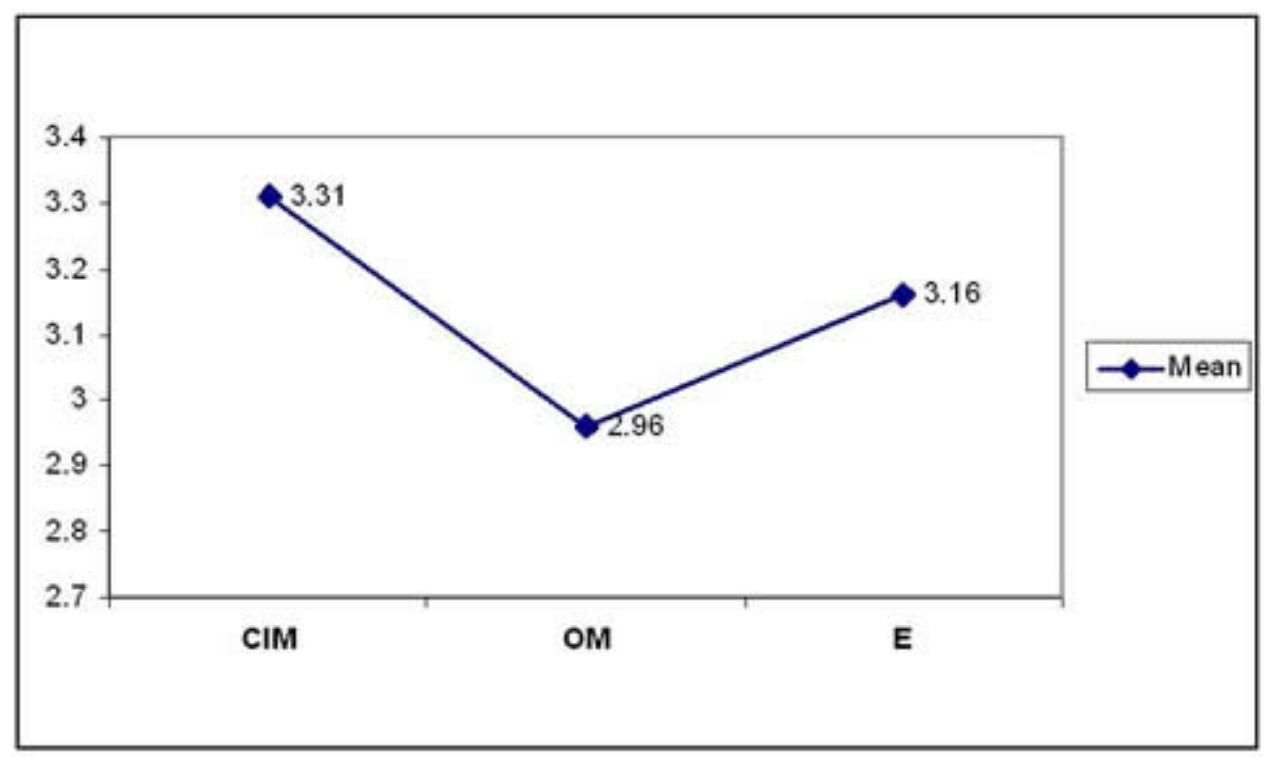

The findings also concluded that the Standard Bank of South Africa's intranet (Blue Matter) was recognized by employees (94,2\%) and that it was used at least once a week by $70 \%$ of the respondents (Figure 3). The results also showed that respondents felt that the Blue Matter content did not contain the latest available information and only agreed moderately that the intranet was an information solution for them. It was recommended that the Standard Bank of South Africa review and update the content of their intranet more regularly.

Figure 3 Usage of the Standard Bank of South Africa's intranet (Blue Matter)

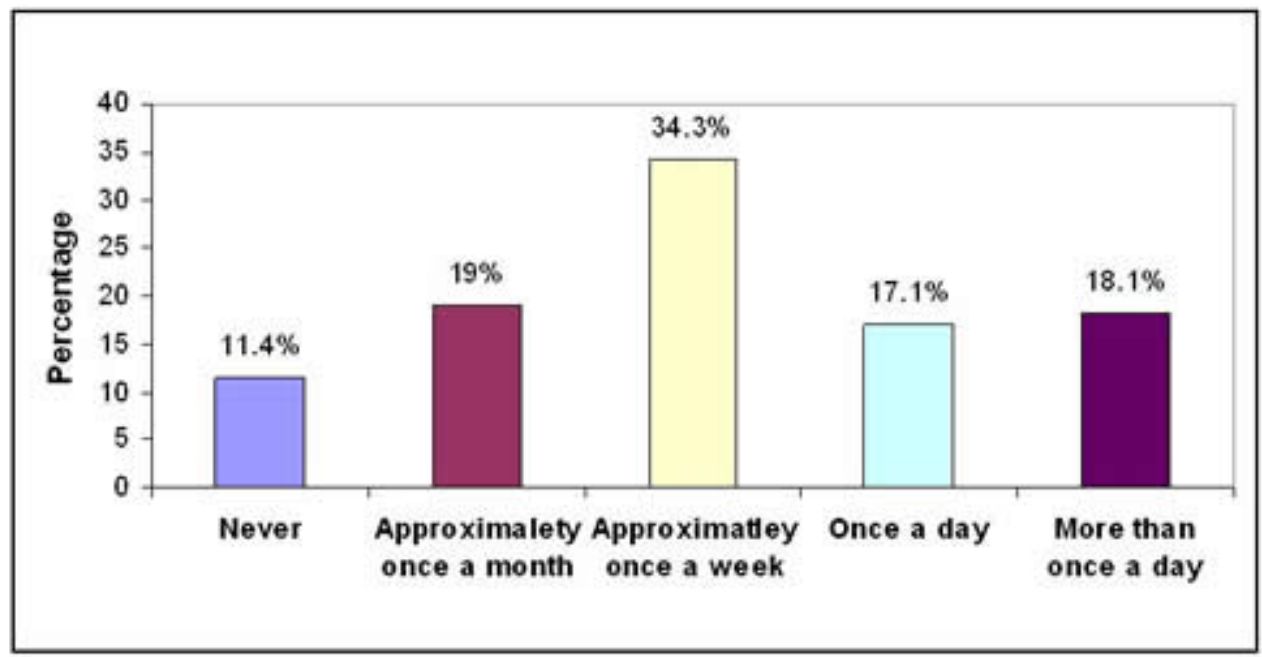

\section{Electronic communications}

The Information Age has caused changes in social, cultural and economic environments for many individuals and organizations through the use of electronic channels. There are many different electronic communication mediums and channels available such as broadcasting, telephone and the Internet. Broadcasting channels include video conferencing, radio and television.

Telephones have a wide range of options, including voice mail, conference call, facsimile via 
landlines and cellular phones. New devices to be added to this are smart phones with PDAlike functionality.

The Internet is used by people in all walks of life, from administrative assistants to CEOs and from blue-collar workers to politicians. Although the Internet is the newest medium for information flow, it is the fastest growing medium of all time, becoming the information medium of first resort for it users. Daily activities done world-wide by users on-line include:

- Sending e-mail

- Getting news

- Using a search engine to find information

- Surfing the WWW for fun

- Looking for information on a hobby

- Doing a WWW search to answer a specific question

- Doing any type of research for their job

- Researching a product or service before buying it

- Checking the weather

- Sending an instant message.

Some of the features and functions that the Internet can offer a user are the WWW, blogs, email, instant messaging (IM) and peer-to-peer (P2P) file sharing. E-mail is one of the most important.

\subsection{E-mail}

E-mail is used by more than 650 million people globally and is the most well-known mode of computer-mediated communication (Crystal 2001). With businesses conducting transactions at electronic speed and operating globally, users meet most people with whom they communicate through electronic communication such as broadcasting. Yet, most communication will be formal letters or memoranda sent to recipients through e-mail.

It is clear that e-mail is a mission-critical component for communication and information collection and dissemination. It has various advantages as well as disadvantages that can be costly for the users and organizations. Cavanagh (2003) indicates that people like e-mail for the following reasons:

- E-mail enables people to send and respond at their convenience.

- It encourages a quick response in real time.

- E-mail enables the sender to distribute the same message to many parties.

- E-mail provides an audit trial.

- It facilitates the easy transfer of data and information.

\subsection{Writing styles of e-mail users}

A huge number of people use e-mail globally. Many stylistic features, such as the writer's age, gender, purpose, mood, reliability, experience, confidence and education will influence the way the writer writes an e-mail.

As there is a lack of standardization, individuals all write e-mails differently, but over time become aware of e-mail etiquette. Flynn and Kahn (2003) indicate netiquette guidelines for employees. Adherence to basic rules of netiquette can alleviate many problems. Some of these guidelines include:

- Beware of hidden readers 
- Write as though your mother is reading

- Remain gender neutral

- Keep the organization's electronic communication policy in mind

- Do not use e-mail to let off steam

- Control the urge to 'flame'

- Respect others' time

- Never reply to spam

- Incorporate a situation and signature

- Consider e-mail's limitations.

\subsection{Spam}

Users do not only have problems writing e-mails, but can also receive commercial nonsolicited communications or 'spam'. This is a growing problem for many organizations and individuals. Fletcher (2004) gives a simple definition of spam as unsolicited e-mail messages, generally commercial or promotional in nature, that are usually sent in bulk. The key word here is unsolicited. Most spam messages are commercial advertisements for products or services, but many non-commercial messages can also be considered as spam, such as:

- Promotional messages

- Political messages

- Press releases

- Charitable solicitations

- Scams and 'get rich quick' schemes

- Jokes

- Chain letters

- Hoax messages that advise the recipient to forward the message.

Fletcher (2004) explains that spam wastes system resources, including bandwidth, mail server processing cycles and storage capacity. Spam can overwhelm mail servers that are not secured against relaying. It wastes human resources, not just the time of employees who read and respond to spam, but that of administrators and help desk personnel as well. Spam can violate corporate policies regarding the non-business use of company messaging systems. Offensive or pornographic spam can also violate corporate anti-harassment policies.

The results from the empirical study concerning this section concluded that e-mail was the most used Internet application for business purposes (Figure 4).

Figure 4 Internet applications for business purposes 


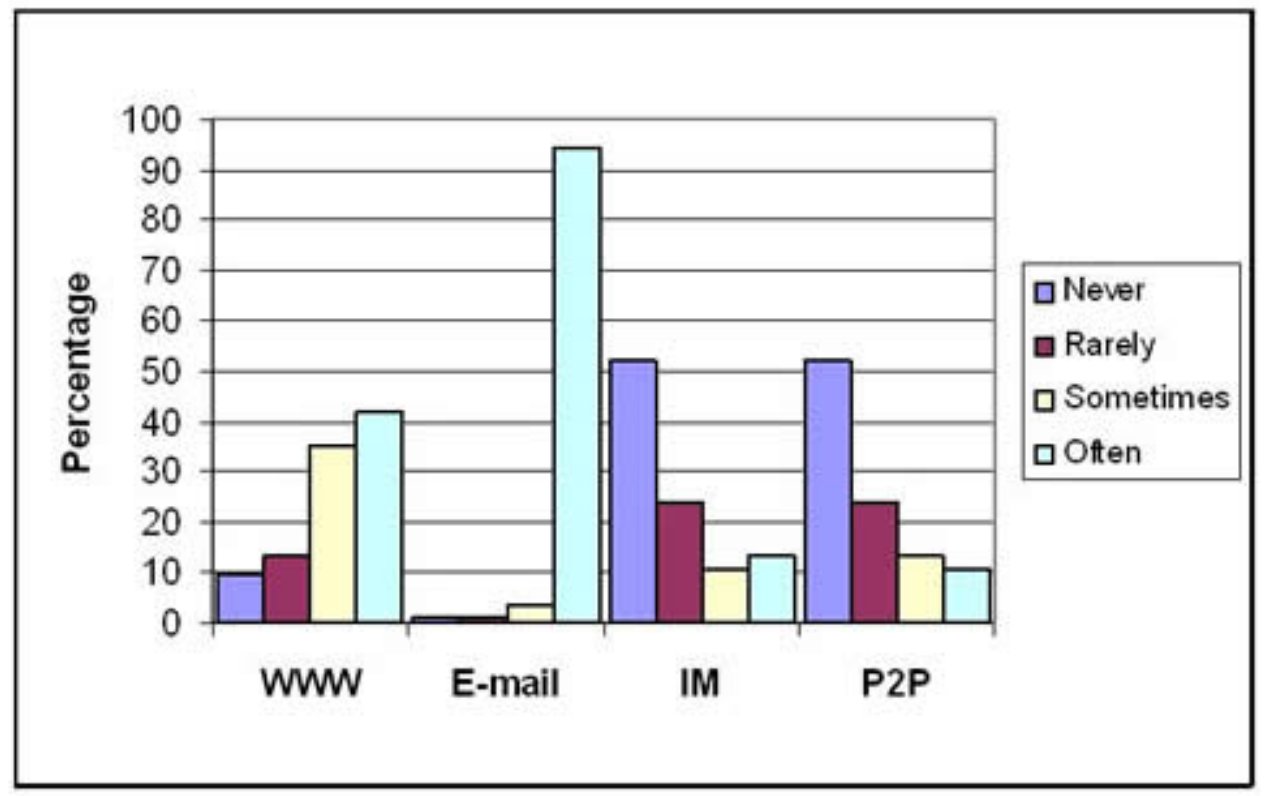

For the factor analysis, three e-mail characteristics were identified. The first factor (characteristic) analysed was efficacy. Respondents felt that e-mail reduced the number of face-to-face meetings and the number of phone calls. This means that the social structure of organizations and users was affected by e-mail usage. They also agreed that e-mail was an efficient way of communicating.

The second factor analysed was communication. The results showed that e-mail improved communication with managers, other departments and colleagues. Respondents also agreed that e-mail was an effective way of communicating.

The last factor analysed was convenience. Respondents agreed strongly that e-mail was convenient and fast, that it made information easily accessible and that it saved on costs.

Respondents $(60,8 \%)$ received spam only to a small extent in their work e-mail inboxes as indicated in Figure 5. This shows that the controls and regulations used by the Standard Bank of South Africa for controlling spam were working well. Most respondents received spam in their personal e-mail inboxes to a small to moderate extent, which showed less rigorous controls in their personal mail system. Therefore most employees followed the ecommunication policy whereby users may not use the group's e-communication services in a manner that wasted the resources provided by these services or generate unnecessary network traffic.

Figure 5 E-mail spam affecting work and personal e-mail 


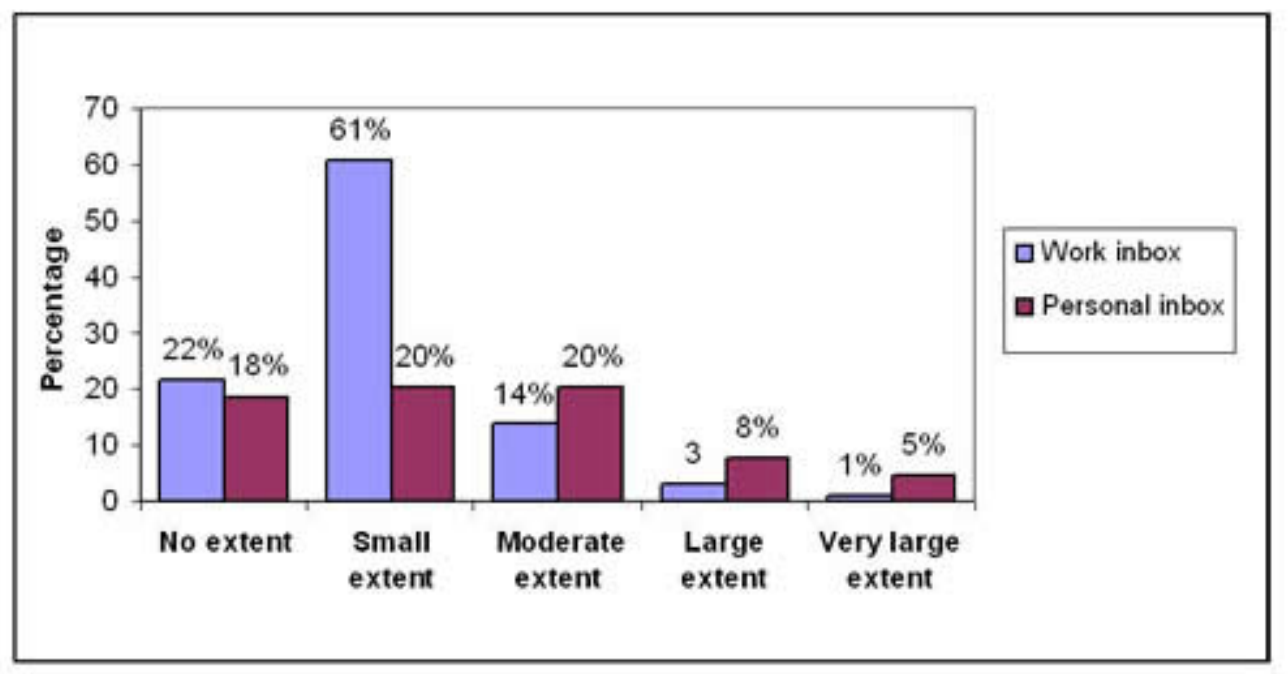

The respondents agreed that spam wasted company resources and that the company should block spam (Figure 6). This was done effectively by the company's security solution, Mail Marshal. The product effectively protected the company against spam, e-mail viruses and malicious codes. In addition, it also boosted employee productivity by monitoring and scanning e-mails for spam, offensive e-mails and viruses.

Figure 6 Managing e-mail spam

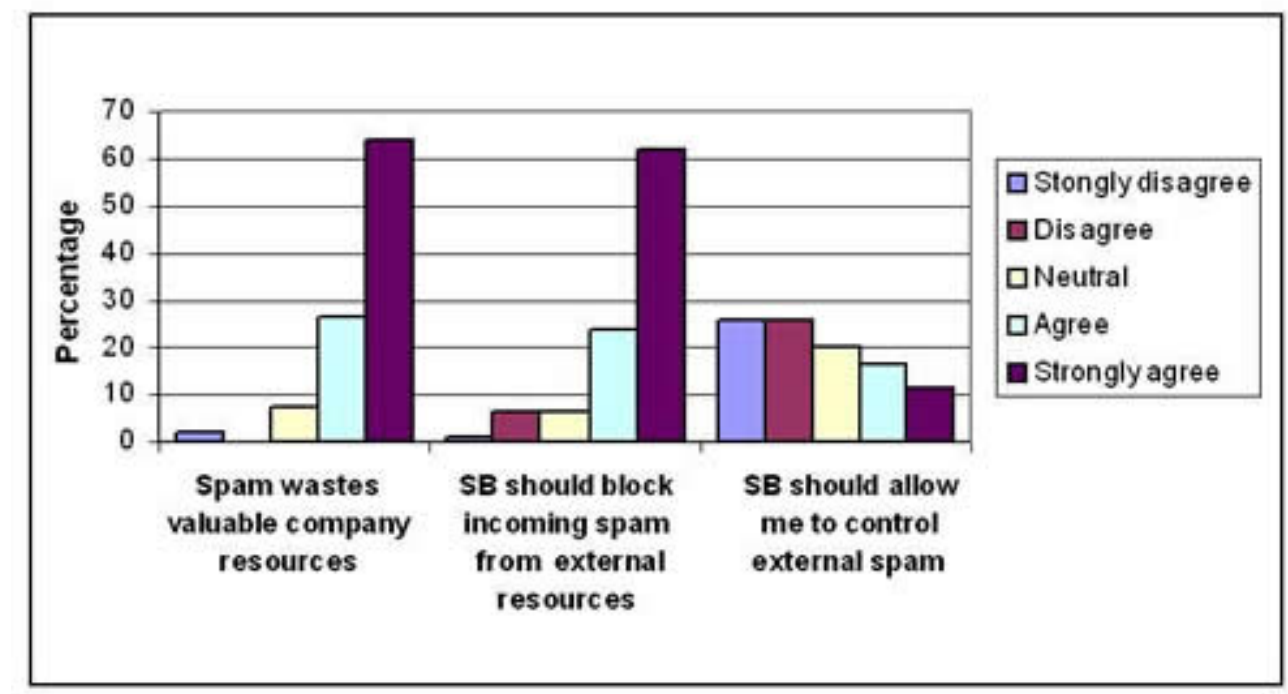

\section{E-mail overload}

E-mail is a method for facilitating unstructured communication among employees, and valuable cross-fertilization of ideas and increased innovation in the organization (Agarwal and Rodhian 2002). Yet, individuals and organizations are faced with an increasing number of e-mail traffic and can be overwhelmed by this. This does not just cause e-mail overload but, more intensely, information overload. Three main causes for e-mail overload are indicated by Mandell (2001):

- Improper use 
- Lack of discipline

- Spamming.

Anon (2001) indicates that as businesses' use of e-mail intensifies, many enterprises struggle to manage their infrastructure. E-mail traffic is putting strain on corporate networks and storage requirements for future use. E-mail overload is also caused by the following (Mandell 2001):

- All the hours devoted to creating, reading and replying to messages

- Waste of resources in bandwidth, server and memory of structural capital of organizations.

Adam (2002) states that e-mail is a communication medium that some people are incapable of being without. It took some time for people to adapt to this new communication medium, but it has changed many users' everyday life. On the other hand, problems resulting from its popularity have become well known, such as information overload, e-mail overload, crime and time spent on e-mail.

E-mail can lead to negative influences and outcomes such as excessive time spent on unproductive work and lack of attention to security. Most organizations encourage employees to use e-mail and communication systems for business-related issues only. Agarwal and Rodhain (2002) explain that, unfortunately, the growth of e-mail has preceded rather than followed the evolution of information technology (IT) policies and, as a consequence, norms rather than orders are used to guide employee behaviour.

E-mail systems have many other measures available to avoid e-mail overload and ensure the effective management of e-mail. Organizations have to create an effective e-mail management system by implementing electronic communication policies. Surveillance and monitoring software can also be integrated to protect organizations against legal confrontation and loss of productivity. Archiving solution software plays a crucial role in keeping companies compliant with legal, clarification and risk management requirements.

The results of the survey showed that $65 \%$ of respondents felt moderately overwhelmed by their e-mail to a very large extent (Figure 7). The results of the questionnaire also pointed out that $75 \%$ of respondents received up to 60 e-mails a day and that $25 \%$ received more that 60 e-mails a day (Figure 8), that is more than 420 e-mails a week and more than 21800 a year. This clearly indicated that respondents were experiencing e-mail overload. Of the respondents, 29\% spent three hours or more a day on work-related e-mails, which was more than a third of their working day (Figure 9). In addition, $45 \%$ of the respondents indicated that they spent less than two hours a day on work-related e-mails. It would be recommended that respondents set a specific time slot in their day to catch up on e-mails, and that they plan their e-mail folders carefully.

Figure 7 Extent of e-mail overload 


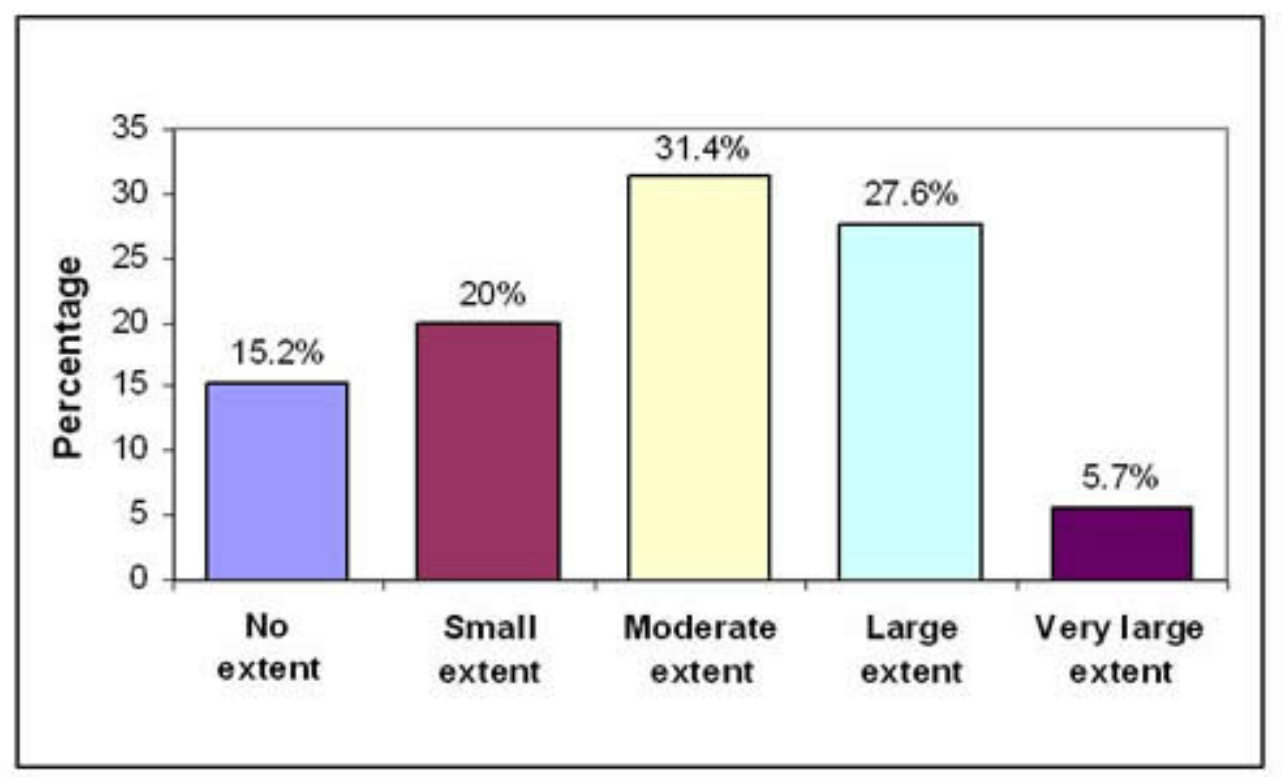

Figure 8 Average work-related e-mails

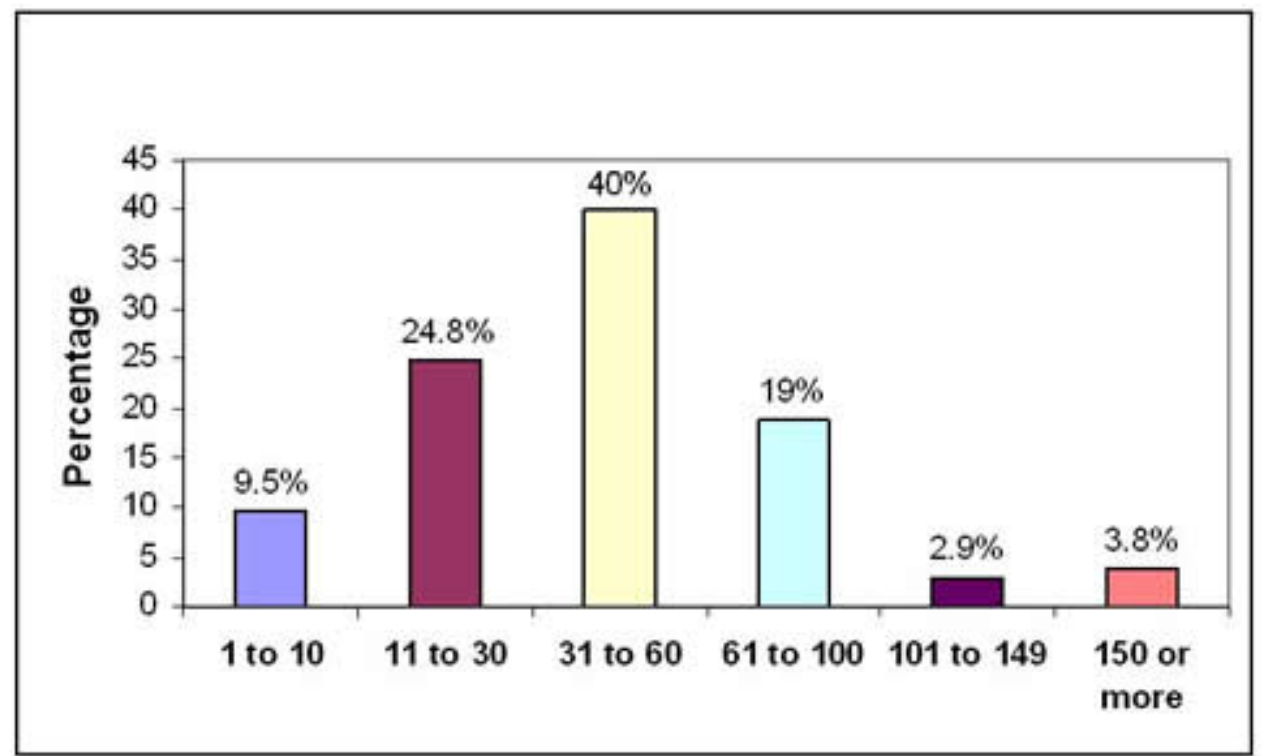

Figure 9 Time spent on work-related and personal e-mails 


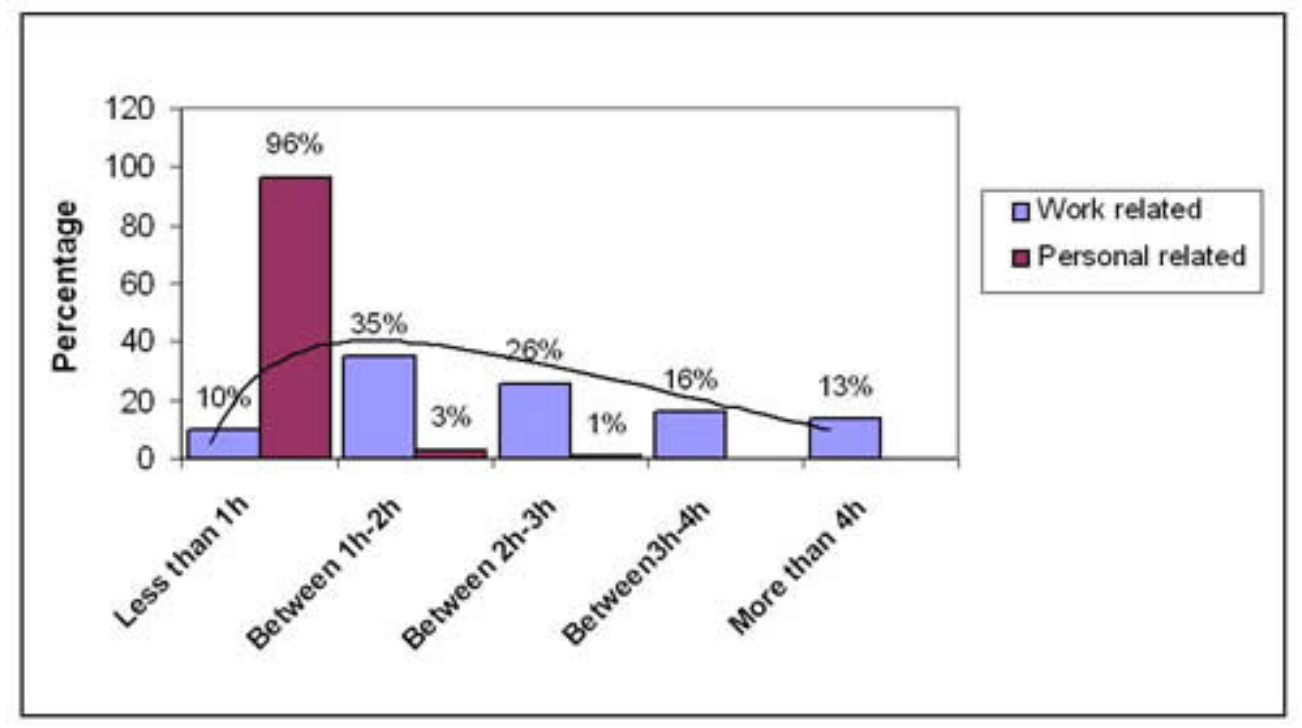

top

\section{Effective management of e-mail within the organization}

Policies, monitoring and surveillance as well as e-mail archiving systems form part of the management of e-mail within the organization.

\subsection{Policies}

Almost every aspect of business now revolves around IT. More and more, the role of IT in business is changing the way it operates. These advances have not come without a cost. Employee use of business computer resources, for example e-mail and Internet access, can subject a company to potential legal liability, compromise confidential information and result in unnecessary problems and an increase in computing cost. Overly (1999) gives examples of problems that can occur:

- Businesses have spent many millions on litigating and settling lawsuits arising from employee abuse and misuse of e-mail. Employees use e-mail to circulate inappropriate jokes, harass and discriminate against co-workers and defame other businesses.

- Trade secrets and other highly sensitive business information stored on computers have been stolen or inadvertently compromised by employees.

- Employee use of the Internet for non business-related activities has seriously compromised corporate security and resulted in millions in lost productivity and increased computing costs.

- Searches of business networks routinely turn up hundreds of megabytes of pornographic material and illegal software loaded by employees.

To reduce these risks the following can be done (Overly 1999):

- Adopt written policies on computer and e-mail use that specifically define the rights and obligations of employees regarding computer resources.

- Companies should conduct training and awareness seminars for employees regarding the proper use of their computers, Internet and e-mail access.

- Organizations can install appropriate monitoring and filtering software to prevent access to inappropriate material and to identify problem employees.

Despite the growing use of computers, Internet and e-mail access in the workplace, and its 
potential for liability, few companies have established written guidelines relating to employee use of computerized systems. Businesses have to be aware of the potential pitfalls that go along with this new technology and protect themselves by adopting appropriate guidelines and policies. Non Profit Hub (2005) states that e-mail policies are risk management strategies that establish the acceptable use of company e-mail accounts, shielding an employer from legal liability and protecting network security and productivity.

Organizations must publish and follow strict guidelines to control the use of trade secrets and information in e-mails and other electronic communications. Companies should set up policies that will remind employees of their duty to protect trade secrets from unauthorized disclosure and the fact that it is in everyone's best interest. Monitoring and surveillance are part of policies and companies and employees should be aware of their responsibilities and restrictions when using corporate communication network systems. The Standard Bank of South Africa has many effective policies including the following:

- Information security framework policy

- Electronic communication policy

- Computer user policy

- Remote access policy

- Privacy policy

- Computer and network management policy

- Information access control policy

- Computer virus control policy

- Mobile equipment policy.

Respondents agreed that the hardware, software and computer-held information in their office environment belonged to the Standard Bank of South Africa (Figure 10). This shows that they complied with the Computer User Policy.

It would be recommended that the policies mentioned above be regularly updated with changes in legislation and technology. Employees also need to be informed of these changes and how they could effect them and their electronic communication channels usage (e.g. email). Employees also agreed that formal archiving should be implemented.

Figure 10 Need for archiving and the office environment of the Standard Bank of South Africa

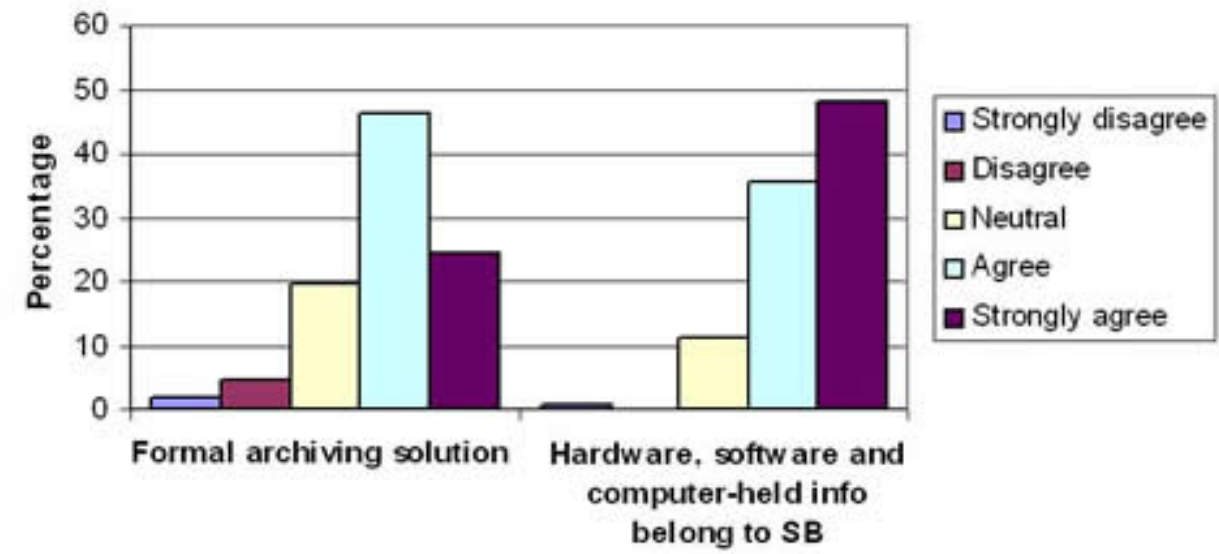




\subsection{Monitoring and surveillance}

Companies are continuously adding monitoring and surveillance tools to their communication systems to combat legal liability, reduced productivity and the threat of exposure of trade secrets and intellectual property. In some cases, employers can be held liable for defamatory, discriminating and sexual harassing statements made by employees. These problems are caused by the misuse of technology and can be very costly. Employers have to strike a balance between keeping an eye on poor performance and protecting the employee's rights to privacy if monitoring policies are to succeed.

Watson (2002) claims that the market for e-mail surveillance is expanding rapidly and that there is a wide range of products and services available, with different capabilities. These tools enable an information system's operator to track exactly where an e-mail message is in the supply chain - from the recipient's inbox to the information service provider of the sender.

The questionnaire results indicated that respondents (66\%) believed that their e-mails were monitored. This was done by Mail Marshal, as mentioned before. Respondents also agreed that e-mails should be monitored to track misuse, to track the dissemination of information to unauthorized third parties, and to protect the company's trade secrets as indicated in Figure 11.

Figure 11 Attitude towards the monitoring of employee e-mails

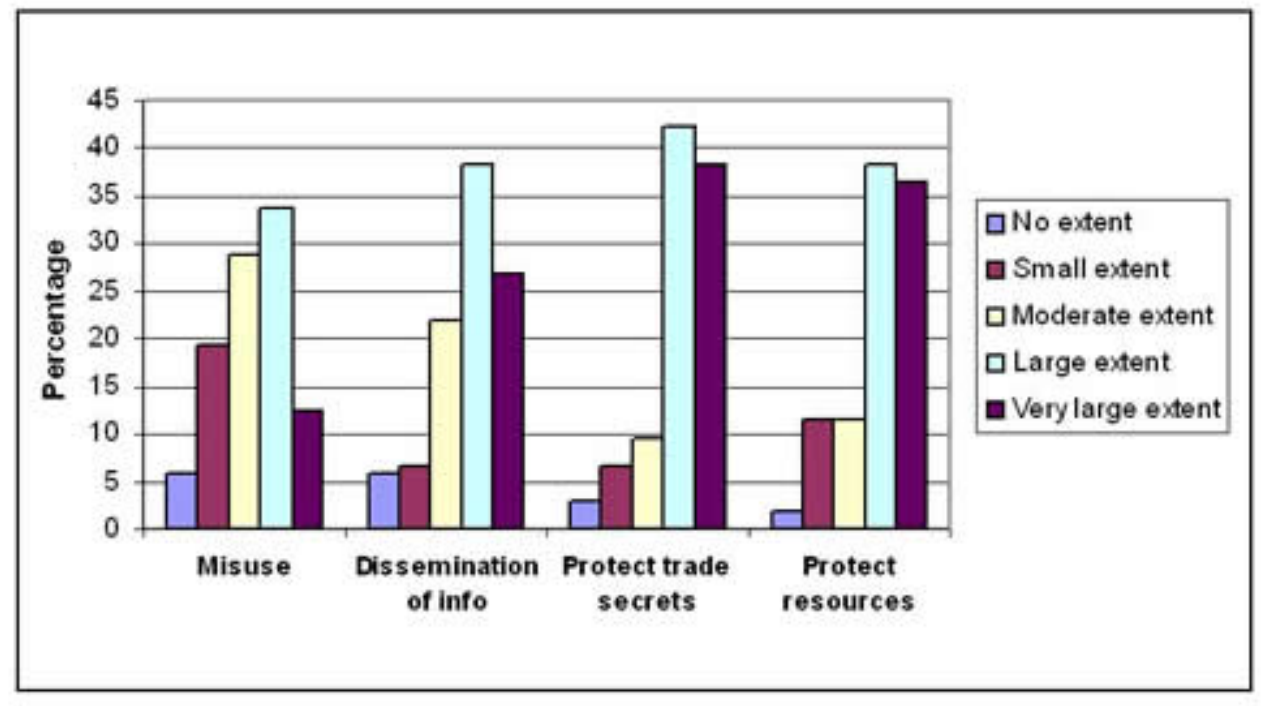

\subsection{Archiving}

It is inevitable that the use of electronic communication within the corporate environment will continue to rise. With regulatory compliance, legal discovery and storage management concerns growing, the question is not whether organizations will need an archiving solution, but rather when it will need one. The implementation of e-mail archiving can ease e-mail management to a large extent. Roberto (2004) explains the benefits that a proper archiving system can deliver:

- Searches and immediate delivery are possible

- E-mail can be checked and retrieved and the content is structured

- Compliance with regulators and laws is ensured

- The size of e-mail databases is reduced 
- Performance and efficiency of the e-mail system is improved

- Users and administrators are less overburdened.

The use of e-mail archiving software is growing exponentially, fuelled by the explosion of email messages and other electronic communications, as well as by concerns about regulatory compliance and other factors (eWeek 2005).

The Standard Bank of South Africa has not yet implemented a formal archiving system and respondents agreed that a formal archiving solution should be implemented (Figure 10). Implementing an archiving solution can significantly lower costs, improve IT processing within the organization and potentially deliver a return on investment. When an archiving solution is implemented, formal training should be given to employees to ensure that they know and understand the new solution.

Results of the questionnaire indicated that only $9 \%$ of respondents had received formal training on e-mail management specifically and that $72 \%$ agreed that formal training is important to very important as indicated in Figure 12.

Policies should also be communicated to ensure that users know exactly what is required of them and the reasons behind these requirements. Ideally, the Standard Bank of South Africa should continue to link the policy rules to employee PC desktop screens.

Figure 12 Importance of e-mail training

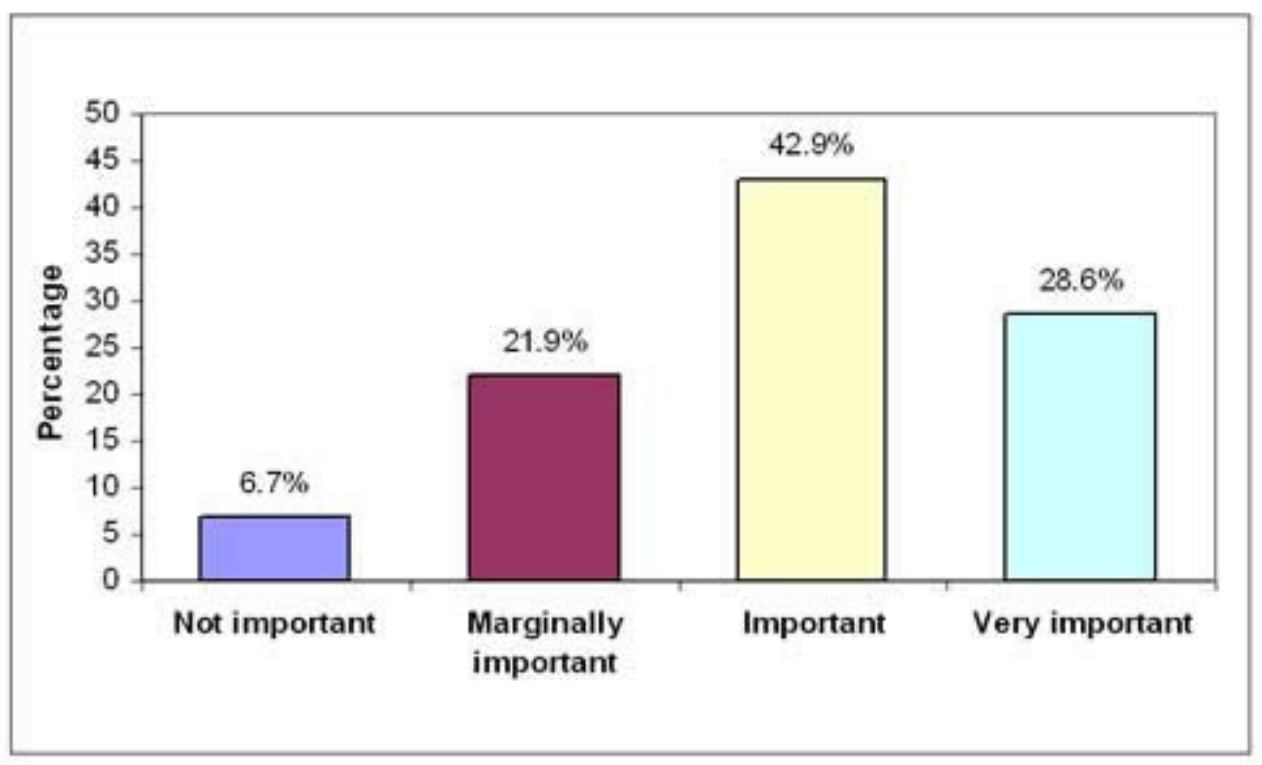

\section{Conclusion and future areas of research}

The information workers of today have a wide range of information sources available for decision making. Respondents in this research felt moderately overloaded by the amount of information they received every day at work, which influenced their physical well-being, relationships with colleagues, friends and family.

E-mail is the most used computer-mediated application and is used more than the WWW, instant messaging or peer-to-peer file sharing. More than half of the respondents in this research felt overwhelmed by the number of e-mails they received every day. A quarter of 
the respondents received more than 60 e-mails per day. Almost a third of respondents dedicated three hours or more to e-mails a day. It is recommended that respondents should have a time slot in their day to respond and create e-mails.

It is clear that formal training in e-mail management should make a significant difference in the usage of e-mail within the organization to reduce e-mail overload. Further research should be done in the following areas:

- E-mail protocols and codes of conduct to reduce stress caused by e-mail overload

- Archiving, monitoring, retrieval of e-mail and a code of conduct for employers vs the privacy rights of employees

- The planning of office time to cater for the e-mail burden.

\section{References}

Adam, R. 2002. Is e-mail addictive? Aslib Proceedings 54(2):85-94.

Agarwal, R. and Rodhain, F. 2002. Mine or yours: e-mail privacy expectations, employee attitudes, and perceived work environment characteristics. Proceedings of the 35th Hawaii International Conference on Systems Science.

Anon. 2001. The e-mail overload (1). Business Europe ABI/Inform Global 41(20):3.

Bawden, D., Holtham, C. and Courtney, N. 1999. Perspectives on information overload. Aslib Proceedings 51(8):249-255.

Cavanagh, C. 2003. Managing your e-mail - thinking outside the inbox. Hoboken, New Jersey: John Wiley \& Sons Inc.

Crystal, D. 2001. Language and the Internet. Cambridge: Cambridge University Press.

Du Plooy, G.M. 2002. Communication research: techniques, methods and applications. Landsdowne: Juta.

eWeek. 2005. Compliance worries drive e-mail archiving market. General Business File ASAP, article nr: A127130175 (January).

Fletcher, S. 2004. Verbal communication with the innovation manager, Web channel department, Standard Bank.

Flynn, N. and Kahn, R. 2003. E-mail rules. A business guide to managing policies, security, legal issues for e-mail and digital communication. New York: AMACOM.

Lyman, P. and Varian, H. 2003. How much information? [Online]. Available WWW: http://www.sims.berkeley.edu/research/projects/how-much-info/. (Accessed 17 March 2007).

Mandell, M. 2001. Preventing e-mail overload. World Trade ABI/INFORM Global 14(5):4446.

Non Profit Hub 2005. E-mail policies [Online]. Available WWW:

http://www.nonprofithub.com/email-policies.htm. (Accessed 15 August 2006). 
Overly, M.R. 1999. E-policy - how to develop computer, e-mail and Internet guidelines to protect your company and its assets. SciTech Publishing Inc. USA.

Roberto, M.K. 2004. E-mail archiving - a key piece to compliance strategy. Computer Review, ABI/INFORM Global 24(10):20.

Watson, G. 2002. E-mail surveillance in the UK workplace - a management consulting case. Aslib Proceedings 54(1):23-40.

\section{Disclaimer}

Articles published in SAJIM are the opinions of the authors and do not necessarily reflect the opinion of the Editor, Board, Publisher, Webmaster or the Rand Afrikaans University. The user hereby waives any claim he/she/they may have or acquire against the publisher, its suppliers, licensees and sub licensees and indemnifies all said persons from any claims, lawsuits, proceedings, costs, special, incidental, consequential or indirect damages, including damages for loss of profits, loss of business or downtime arising out of or relating to the user's use of the Website.

ISSN 1560-683X

Published by InterWord Communications for Department of Information and Knowledge Management, University of Johannesburg 